X. P. Xu, L. He, C. Z. Xia* and J. S. Zou

\title{
Microstructure and Interface Bonding Strength of WC-10Ni/NiCrBSi Composite Coating by Vacuum Brazing
}

https://doi.org/10.1515/htmp-2017-0127

Received September 12, 2017; accepted April 09, 2018

Abstract: WC flexible cloth was fabricated by rolling WC powder that was pre-mixed with a nano-scale binder. BNi-2 braze alloy was used to braze the WC flexible cloth to a workpiece surface in a vacuum to form a compact composite coating. The composite coatings with different percentages of WC (wt.\%, 30\%, 50\% and $80 \%$ ) have been successfully brazed onto Q345 steel substrate. Microscopic morphology and interfacial structure were characterized in terms of porosity, segregation and the distribution of WC particles. The bonding strength between the coating and the substrate was evaluated by shear test. The results showed that the segregation of WC particles appeared in all three coatings. With the increase of WC content in the coating, the segregation phenomenon was gradually reduced, and the WC particles were more closed. Furthermore, the thickness of the coating and matrix reaction layer was narrower, and more holes were found in the coating. Fracture of the $30 \%$ and $50 \%$ WC coatings was mainly plastic fracture, and the fracture of the $80 \%$ WC coating was mainly brittle fracture accompanied by local plastic fracture. The maximum bonding strength of the coating to the substrate was determined to be $302 \mathrm{MPa}$.

Keywords: brazing, WC-10Ni/NiCrBSi metal cloth, composite coating, microstructure

\section{Introduction}

Friction and wear are two of the main forms of failure of various metal workplaces in mechanical equipment, which lead to great economic losses. According to

*Corresponding author: C. Z. Xia, Provincial Key Lab of Advanced Welding Technology, Jiangsu University of Science and Technology, Zhenjiang, Jiangsu, 212003, China, E-mail: cz_xia@126.com

X. P. Xu: E-mail: xxpjust@126.com, L. He: E-mail: heliztn@126.com, J. S. Zou: E-mail: zjzoujs@126.com, Provincial Key Lab of Advanced Welding Technology, Jiangsu University of Science and Technology, Zhenjiang, Jiangsu, 212003, China incomplete statistics, the loss of abrasive wear in five departments of metallurgy, electric power, building materials, coal and agricultural machinery, the annual direct loss of consumption funds amounts to $4 \sim 5$ billion dollars. Therefore, research on improving the wear resistance of materials has been paid increasing attention both at home and abroad [1-5]. With the development of high-end industries, such as mold and oil exploitation, higher requirements for the surface properties of materials have been put forward. The traditional methods of improving surface properties were thermal spraying, surfacing, hard alloy insert and gas phase deposition. However, with the increase in workplace requirements, these wear-resistant methods were unable to meet the needs of industrial applications because of their shortcomings. The strength of thermal spray bonding can only reach $5-30 \%$ of the parent material, and the highest achieved was only 70 MPa. Because of uneven heating and large temperature gradients in the welding process, it is easy to produce greater stress and deformation after welding, and cracks may even occur. The wear layer obtained by the vapor deposition method was too thin and the thickness was usually only a few microns to a few hundred microns [6-11].

Tungsten carbide and nickel base tape filler metal through high temperature vacuum brazing could form WC cemented carbide. This WC cemented carbide could be widely used in the wear-resistant tool industry and grinding tool industry. WC metal cloth with a sticky band could also overcome the problem of complicated size and position of workplaces. Compared with the above methods, WC coating prepared by vacuum brazing had less porosity, hard phase decomposition and controllable coating thickness. The coating produced by vacuum brazing has little internal stress [12-14]. However, previous research on WC hard alloy mainly focused on the macro aspect, the relationship between composition ratio and coating properties, and there is a lack of in-depth research on the microscopic mechanism of WC brazing. Previous researches could not fundamentally explain the performance of coating [15-18]. 
In this paper, we aimed to address the basis of the problem of the current research status of WC hard alloy at home and abroad. The microcosmic mechanism of the brazing process was analyzed by studying the microstructure and interface structure of WC-10Ni/NiCrBSi composite coating after vacuum brazing.

\section{Experimental}

The WC metal cloth used in the experiment consists of two diameters of $30-45 \mu \mathrm{m}$ and $15-20 \mu \mathrm{m}$, two kinds of WC powder, 30-45 $\mu \mathrm{m}$ BNi-2 brazing alloy, and a small amount of binder. In an electronic balance meter, according to the proportions of a certain quality, the WC powder, BNi-2 brazing alloy and binder were weighed and then mixed evenly and then with a roller machine repeatedly rolled into a sticky strip with a thickness of $1 \mathrm{~mm}$. Metal cloth with a WC mass fraction of $30 \%, 50 \%$ and $80 \%$ was prepared in this experiment. BNi-2 brazing alloy fabric of $1 \mathrm{~mm}$ thickness was prepared by the same method, as shown in Figure 1 . The brazing substrate was Q345 steel, and the size was $70 \mathrm{~mm} \times 25 \mathrm{~mm} \times 5 \mathrm{~mm}$. Oxide and grease on the surface of the base metal should be strictly cleared by using $800 \#$ sandpaper, and cleaned in acetone solution by ultrasonic wave. Before the experiment, put WC metal cloth, BNi-2 filler cloth and Q345 steel into the brazing furnace according to the order of brazing of WC metal cloth/BNi-2 filler cloth/Q345 steel, as shown in Figure 2. The vacuum degree was not less than $2 \times 10^{-3} \mathrm{~Pa}$ in the brazing process. After the experiment, $15 \mathrm{~mm} \times 5 \mathrm{~mm}$ samples were taken out. The interface structure and element distribution were studied by SEM, EDS and other microscopic methods. The phase composition of the coating cross section was analyzed by $\mathrm{X}$ ray diffractometer XRD-6000, and the shear test of the coating was carried out.

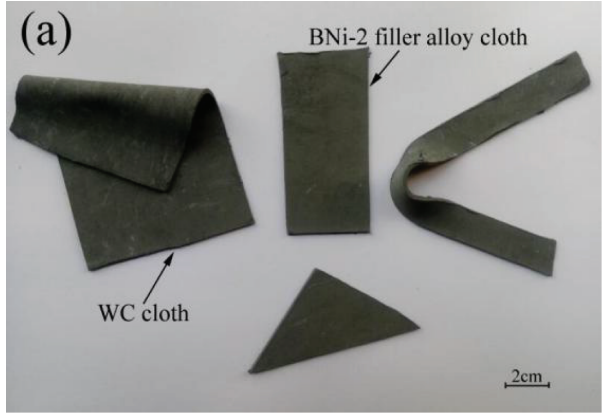

(a) Macroscopic morphology of metal cloth

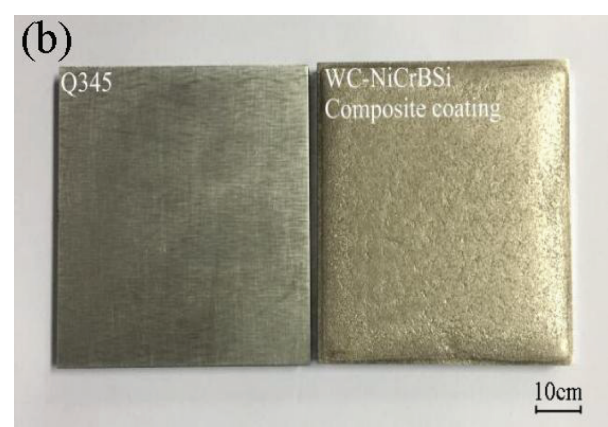

(b) Macroscopic morphology of coating surface

Figure 1: macroscopic morphology of metal cloth and coating surface:(a) macroscopic morphology of metal cloth, (b) macroscopic morphology of coating surface.

(a)

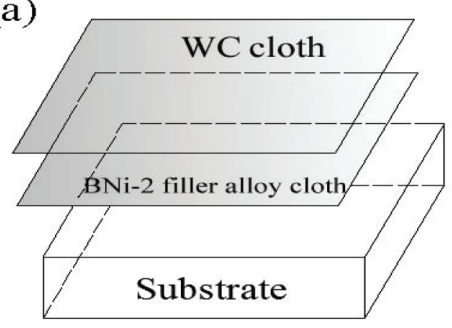

(a) Coating assembly sequence

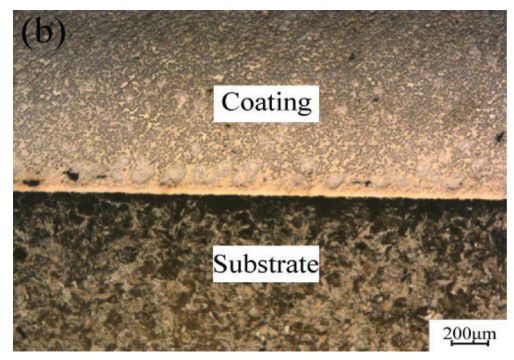

(b) Macroscopic morphology of coating cross section

Figure 2: order of coating assembly and macroscopic morphology appearance of section:(a) coating assembly sequence, (b) macroscopic morphology of coating cross section. 


\section{Results and discussion}

\section{Cross section microtopography and micro- structure analysis of the coating}

Figure 3 shows the cross section microtopography and morphology of the three composite coatings under scanning electron microscope. The round, granular WC was surrounded by Ni-based solid solution and compounds, and the organic binder evaporated from the coating during vacuum brazing. The coatings with different WC content showed different microscopic morphology. As shown in Figure 3, the structures of the three WC composite coatings exhibited segregation of WC particles; $30 \%$, and $50 \%$ WC composite coatings were divided into three regions, I, II, III, and $80 \%$ WC composite coatings were divided into two regions, II, III. Region IV in Figure 3 is the Q345 substrate. Regions I and III in Figure 3 (b) were scanned by EDS for element points and element contents are shown in Table 1. In the characteristic region 1, the main element was $\mathrm{Ni}$, while the content of element $\mathrm{W}$ was very small, which showed that the content of WC in the region was lower. Settlement of WC formed the region I because the WC density was higher than NiCrBSi. Region II was the NiCrBSi-WC composite coating. In the test, WC-10Ni

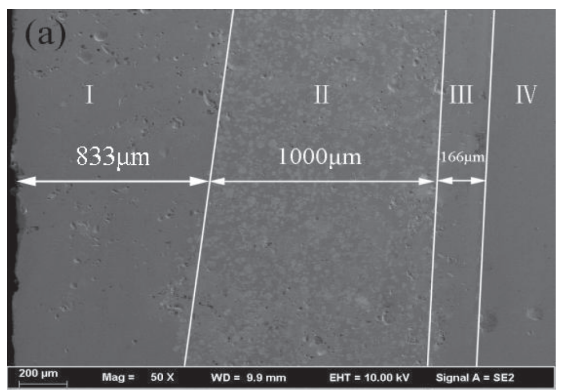

(a) $30 \%$
Table 1: Chemical composition characteristics of region I (wt.\%).

\begin{tabular}{lrrrrrrr}
\hline region & B & C & Si & Cr & Fe & Ni & W \\
\hline A & 3.40 & 6.12 & 3.93 & 2.79 & 2.85 & 79.8 & 1.11 \\
B & 9.17 & 24.94 & 1.44 & 2.28 & 2.63 & 59.08 & 0.46 \\
\hline
\end{tabular}

was used as the reinforcing phase. During deposition, the Ni wrapped on the WC surface to dissolve into NiCrBSi solder, which could improve the wettability of NiCrBSi to WC. At the same time, the molten solder entered zone II for wetting and filling because of capillary action. Zone III was the coating and substrate reaction layer, mainly connecting the coating with the substrate. In terms of microstructure, region III contained almost no WC. The analysis showed that the elements $\mathrm{Si}$ and $\mathrm{B}$ in the solder had stronger diffusion ability and could lower the melting point. Si and B diffusion to zone II would lead to an increase in the melting point in this region, which would lead to solidification first occurring in region III. Therefore, WC would not be able to sink into zone III. From the analysis of Figure 3, it was found that with the increase of WC mass fraction, the segregation of WC particles in the coating was gradually weakened, and the arrangement of WC particles was more compact. The thickness of the coating and substrate reaction layer III was

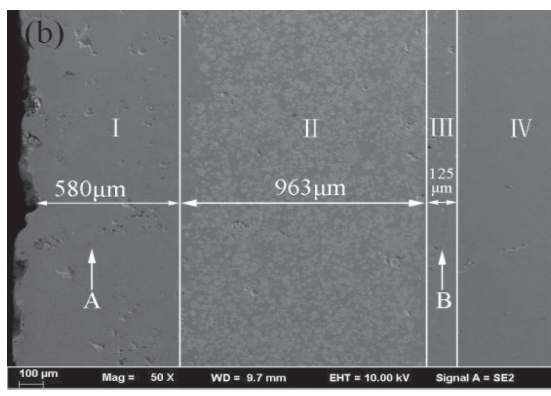

(b) $50 \%$

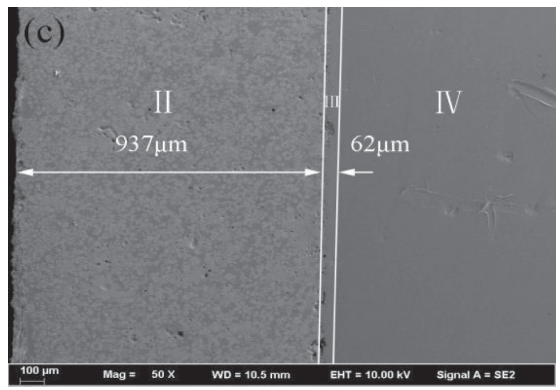

(c) $80 \%$
Figure 3: microscopic morphology and microstructure of coating cross section: (a) $30 \%$, (b) $50 \%$, (c) $80 \%$ 
narrower and more holes were observed. Meanwhile, Figures 3 (a)-(c)show by contrast that the in the $30 \%$ WC coating zone II molding was poor and WC particle distribution was uneven.

In view of the above phenomenon analysis, the capillary flow of the drilling fluid promoted the densification of the coating, while the viscous flow led to the dispersion of the WC particles. The densification and homogenization of the composite coating depended on the combined action of capillary and viscous flow in the brazing fluid. Under the same coating thickness, with the increase of WC particles, the proportion of the BNi-2 brazing alloy decreased, which led to the easier clustering of WC particles and the formation of a skeleton structure. Meanwhile, the viscous flow of the brazing fluid was reduced to make coating dense and homogeneous. The smaller gap between the particles made the capillary action of the drilling fluid increase, and with the increase of WC content the wetting surface area increased. The majority of the solder would be used to fill the gaps between WC particles or wet WC particles, which would reduce the precipitation ability of WC particles and narrow the reaction layer between the coating and the substrate. On the one hand, in the NiCrBSi-WC composite coatings, with the increase of WC particles, the consolidation of WC particles played a pinning effect on the surrounding liquid and solid solution, which resulted in the increase of local micro stress, stress concentration and hole formation. On the other hand, the coefficient of linear expansion of the coating and substrate differed greatly. In the cooling stage, the thinner coating and the base reaction layer could not bear larger stress and formed holes.

The process of surface brazing NiCrBSi-WC composite coatings on low carbon steel could be divided into three stages. The first stage was liquid formation and WC particle rearrangement. When the heating temperature exceeded the melting point of the NiCrBSi brazing alloy $\left(999^{\circ} \mathrm{C}\right)$, as the reinforcing phase, the hard alloy was suspended in the liquid solder, and the liquid filler metal filled the pores between the particles depending on the capillary force formed by the particle gap and its viscous flow. Finally, under the combined action of gravity, capillary force and viscous flow, the WC particles were stably distributed and arranged. In the second stage, the filler elements diffused to the substrate and reacted to form the reaction layer. When the heating temperature was between the melting point of the solder and the brazing temperature, the liquid solder spread to the coating and the substrate to form the brazing seam. The brazing seam played the main connecting role. Because of the concentration difference between the alloy elements in the liquid and the matrix, the element diffusion occurred at the interface, which was accompanied by the first stage. The third stage was the formation of composite coatings. With the decrease of brazing temperature, the composite coating was formed by the solidification of hard phase and brazing fluid. Then the metallurgical bonding was formed between the coating and the substrate.

\section{Interface microstructure analysis}

The morphology of the coating and substrate reaction layer of the three formulations is shown in Figure 4. The three reaction layers were wetted well with the substrate at the interface. The microstructure of the brazing joint was compact and uniform, and WC particles were well wetted. EDS spectrum analysis was used to test the phase composition of the three coatings, as shown in Table 2.

Figure 4 (a) shows a hard white block structure, C region, at the edge of the hard layer and the brazing seam, which contained mainly $\mathrm{Ni}, \mathrm{Cr}, \mathrm{Si}$ and $\mathrm{W}$ elements. Some WC particles began to dissolve at high temperature and diffuse and react with the liquid solder. According to the two element phase diagrams, there were probably $\mathrm{Ni}$ (W), Ni (Cr) solid solution phase and $\mathrm{Ni}_{2} \mathrm{Si}, \mathrm{NiSi}_{2}$ compounds in this area. Compared with the $\mathrm{D}, \mathrm{E}$ region, the content of $\mathrm{Cr}$ element in the $\mathrm{C}$ region was higher. It was considered that the reaction between $\mathrm{Cr}$ and $\mathrm{B}$ formed the $\mathrm{Cr}-\mathrm{B}$ phase. Fe was the main element in the region $\mathrm{E}$ of the joint between the brazing seam and the substrate. At the same time, there was more $\mathrm{Ni}$ and a small amount of $\mathrm{Si}$ and $\mathrm{Cr}$. According to the phase diagram, there may be a gamma (Fe, Ni) solid solution in this region. The brazing seam center $\mathrm{D}$ was rich in $\mathrm{Ni}$ and Fe elements, and had a small amount of $\mathrm{Cr}$ and $\mathrm{Si}$ elements. The solid solution of gamma $\gamma$-Ni (Fe, $\mathrm{Cr}$ ) was mainly formed in this region.

Compared with Figure 4 (a), Figure 4 (b) and (c) shows that the content of $\mathrm{Ni}$ in the joint of the reaction layer and the substrate was less. The analysis showed that, on one hand, the decrease of brazing reaction layer thickness led to the decrease of concentration difference of $\mathrm{Ni}$ content in the reaction layer and substrate, and the diffusion and dissolution of the reaction layer $\mathrm{Ni}$ to the matrix became weaker. On the other hand, with the increase of WC particles, the gap between particles became smaller, and the capillary 


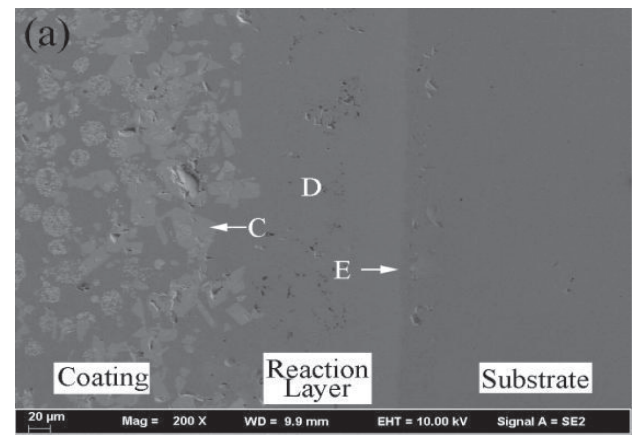

(a) $30 \%$

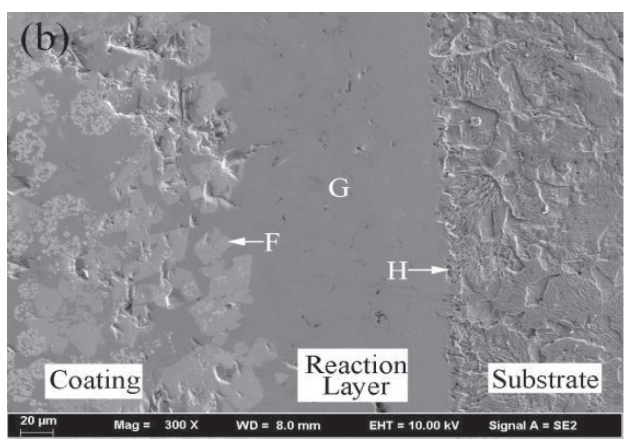

(b) $50 \%$

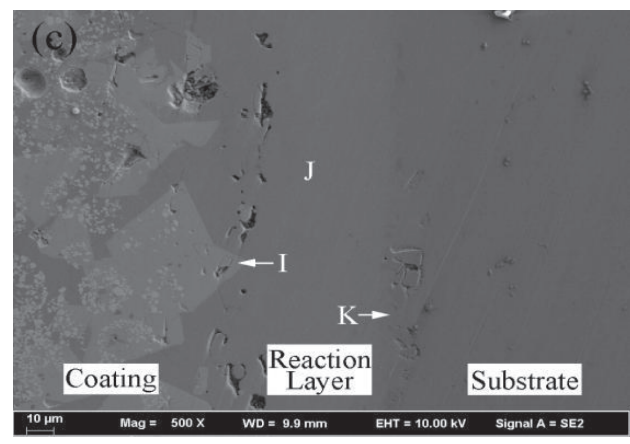

(c) $80 \%$

Figure 4: microscopic morphology and microstructure of reaction layer between coating and substrate:(a) $30 \%$, (b) $50 \%$, (c) $80 \%$.

Table 2: Phase element composition (wt.\%).

\begin{tabular}{lrrrrrr}
\hline region & & $\mathbf{N i}$ & $\mathbf{F e}$ & $\mathbf{S i}$ & $\mathbf{C r}$ & $\mathbf{W}$ \\
\hline White block structure & $\mathrm{C}$ & 33.57 & 0.21 & 14.04 & 32.95 & 19.23 \\
on the edge of & $\mathrm{F}$ & 33.36 & 0.31 & 14.26 & 24.54 & 27.53 \\
brazing seam & $\mathrm{I}$ & 34.01 & 0.52 & 14.79 & 32.41 & 18.27 \\
Brazing Center & $\mathrm{D}$ & 92.47 & 4.27 & 0.37 & 2.89 & 0 \\
& $\mathrm{G}$ & 83.54 & 6.78 & 3.53 & 6.15 & 0 \\
Joint of brazing seam & $\mathrm{J}$ & 70.09 & 18.71 & 4.08 & 7.12 & 0 \\
and substrate & $\mathrm{E}$ & 38.26 & 60.43 & 0.03 & 1.28 & 0 \\
& $\mathrm{H}$ & 28.89 & 68.78 & 1.11 & 1.22 & 0 \\
& $\mathrm{~K}$ & 14.30 & 82.83 & 1.77 & 1.10 & 0 \\
\hline
\end{tabular}

action of the drilling fluid increased, so that $\mathrm{Cr}$ and $\mathrm{B}$ occurred more diffusion in the hard layer. Finally, the melting point of the reaction layer of Figure 4 (b) and (c) was higher than that of Figure 4 (a), and the liquid phase existed for a short time, which was unfavorable to diffusion wetting.

The element composition and distribution of the coating interface had great influence on the compactness and mechanical properties of the coating. EDS was used to scan the line segments LM, NO and PQ in the graph, and the element distribution at the interface is shown in Figure 5 (b), (d) and (f). It was found that the element W hardly diffused to the brazing seam and substrate, and the elements $\mathrm{Ni}, \mathrm{Cr}$ and $\mathrm{Si}$ diffused to the substrate. The Si element was more soluble than the B element in the $\gamma$-Ni solid solution, and the substrate also contained a small amount of the Si element. The distribution of the Si element was mainly concentrated in the hard layer of the brazing seam. The concentration of $\mathrm{Fe}$ in the substrate was much higher than that in the brazing seam. From the curve, $\mathrm{Fe}$ was partly dissolved in the reaction layer between the hard layer and the substrate. Based on the above analysis, the interface between the brazing seam and the substrate was metallurgically bonded, and the brazing seam mainly acted as a combination of coating and substrate. Compared with the $50 \%$ and $80 \%$ WC coatings, two local micro reaction zones were formed in the $30 \%$ WC coating and the substrate reaction layer. Near the hard side, the $\mathrm{Cr}$ and $\mathrm{Si}$ elements appeared more, and near the substrate side the $\mathrm{Ni}$ element also occurred with more diffusion to the substrate. Therefore, excessive WC content was unfavorable to the metallurgical reaction between coating and substrate. 


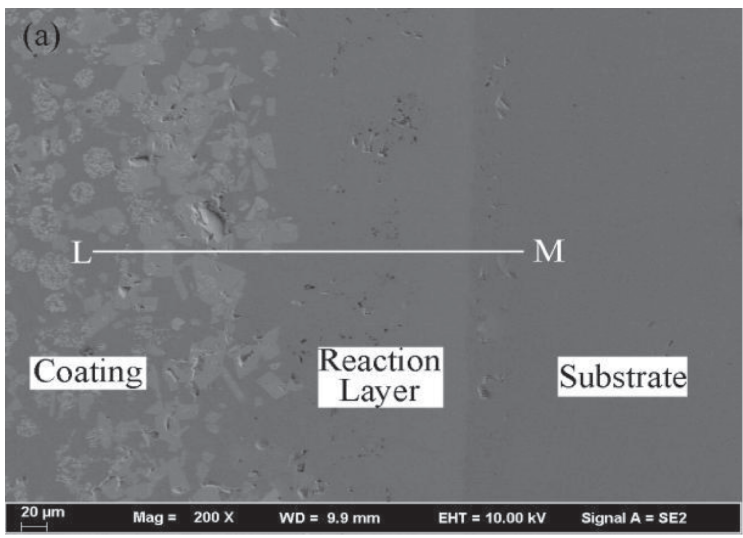

(a) Line scanning positionof $30 \% \mathrm{WC}$ coating

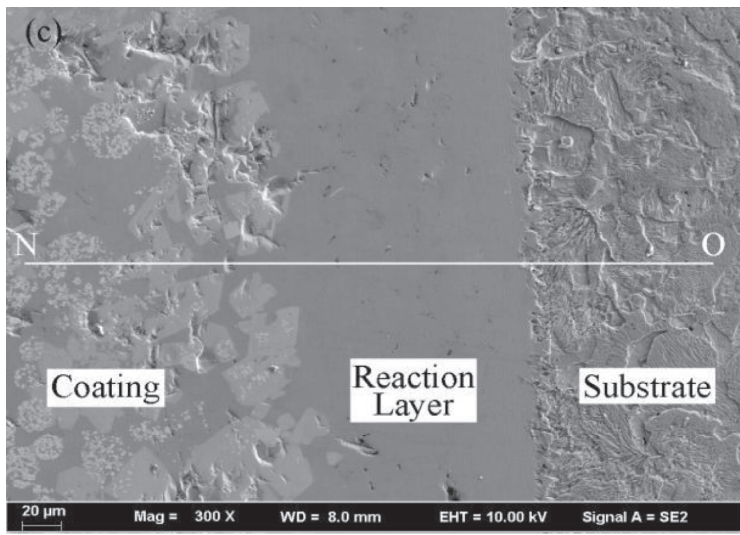

(c) Line scanning position of $50 \% \mathrm{WC}$ coating

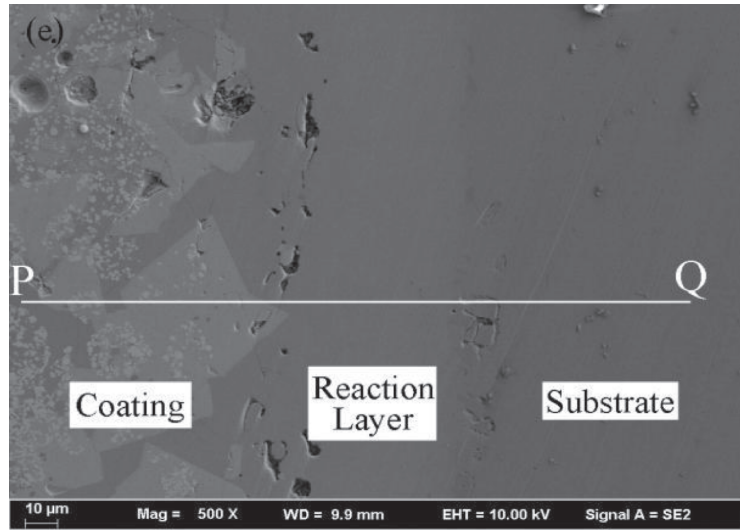

(e) Line scanning position of $80 \%$ WC coating

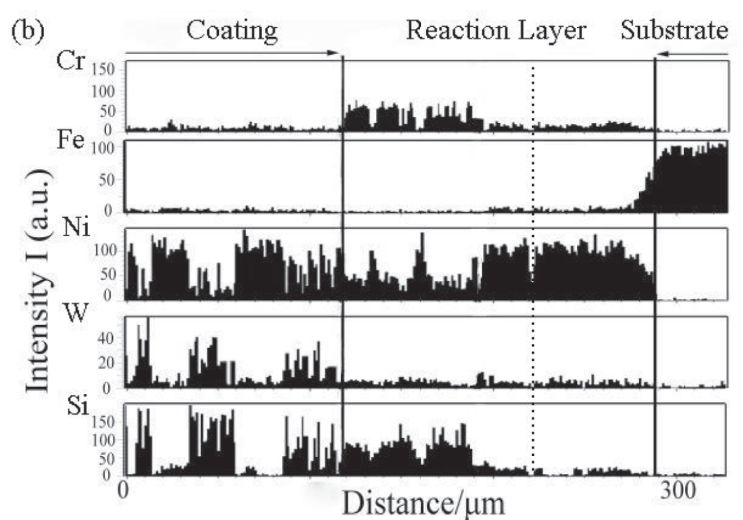

(b) Element distribution of $30 \% \mathrm{WC}$ coating

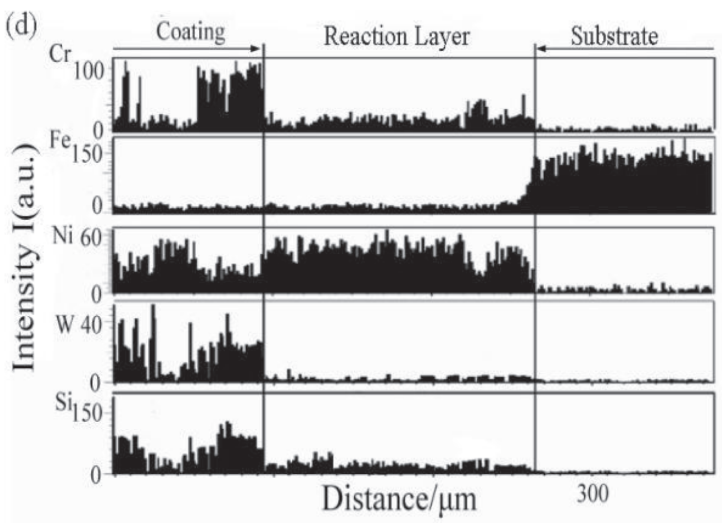

(d) Element distribution of $50 \%$ WC coating

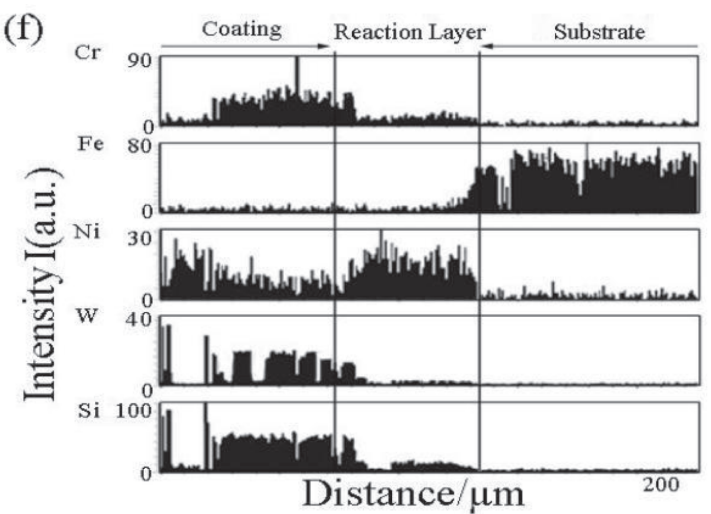

(f) Element distribution of $80 \%$ WC coating

Figure 5: element distribution in brazed interface:(a) line scanning position of $30 \%$ WC coating, (b) element distribution of $30 \%$ WC coating, (c) line scanning position of $50 \%$ WC coating, (d) element distribution of $50 \%$ WC coating, (e) line scanning position of $80 \%$ WC coating, (f) element distribution of $80 \%$ WC coating. 


\section{Phase composition of composite coating}

The surface layer and cross section phase composition of $50 \% \mathrm{WC}$ composite coating were analyzed by $\mathrm{X}$ ray diffractometer, as shown in Figure 6. As shown in Figure 6(a), the main phases of the composite coating were $\mathrm{WC}, \gamma$-Ni solid solutions, and $\mathrm{Ni}_{3} \mathrm{~B}$ phase. $\gamma$-Ni solid solution had a supporting effect on the $\mathrm{WC}$ in the coating, and the $\mathrm{Ni}_{3} \mathrm{~B}$ phase was dispersed in the coating and contributed to dispersion strengthening. The $\mathrm{W}_{2} \mathrm{C}$ and CrxCy brittle compound phases were not found on the surface of the composite coating, indicating that the decomposition of WC on the coating surface did not occur and the wear resistance of the coating was guaranteed. As shown in Figure 6 (b), the main phases of the composite coating were WC, $\gamma$-Ni solid solution, and Fe. Compared with the surface XRD results, there may be $\mathrm{CrB}$ and $\mathrm{Ni}_{3} \mathrm{Si}$ phases. Analysis showed that, because of enrichment in the hard layer near the interface side of the $\mathrm{Si}$ and B elements, the coating section led to the occurrence of WC dissolving and generated some chromium phase and silicide. These $\mathrm{CrB}$ and $\mathrm{Ni}_{3} \mathrm{Si}$ phases were brittle in nature and concentration at the interface would reduce the bonding strength of the interface.

\section{Bonding strength between coating and substrate}

The bonding strength of the WC $-10 \mathrm{Ni} / \mathrm{NiCrBSi}$ composite coating and matrix was evaluated by shear test. The bonding strength between the three coatings and the substrate was $302 \mathrm{MPa}, 252 \mathrm{MPa}$ and $116 \mathrm{MPa}$, respectively, as shown in Figure 8. The fracture morphology was observed under scanning electron microscope, as shown in Figure 7. The characteristic areas in the fracture morphology were analyzed by EDS energy spectrum analyzer, and the chemical composition is shown in Table 3. With the increase of WC content, the shear strength of the coating decreased gradually, and the delamination phenomenon was more obvious. No obvious cleavage steps were found in Figure 7 (b) and (d), which mainly consist of cleavage platform end face and large tearing dimples. The $\mathrm{R}$ region mainly contained $\mathrm{Ni}, \mathrm{Si}$, $\mathrm{Fe}$, and a small amount of $\mathrm{Cr}$ element, and the microstructure was $\gamma$-Ni ( $\mathrm{Si}, \mathrm{Fe}$ ) solid solution and brittle phase $\mathrm{Ni}_{3} \mathrm{Si}$. There may be also be $\mathrm{Ni}_{3} \mathrm{~B}$ brittle phase. These brittle phases were the weak region of the whole fracture, and the crack was formed first under the shear force. The $\mathrm{S}$ region did not contain any Si element, which mainly produced $\gamma$-Ni (Fe, $\mathrm{Cr}$ ) solid solution. Under the action of shear load, the crack grew into a tearing dimple.

From Figure 7 (e) and (f), delamination appeared in the macro fracture. The whole fracture surface appeared to have obvious cleavage features, and plastic fracture existed in some area. The fracture was a mixed fracture in general. Among them, the shear fracture of the $\mathrm{V}$ and $\mathrm{W}$ regions showed completely different microscopic morphology. The $\mathrm{V}$ region had slight plastic dimple features, and the $\mathrm{W}$ region was a typical cleavage fracture. By scanning electron microscopy, $\mathrm{Ni}, \mathrm{Cr}$ and $\mathrm{Si}$ elements were enriched at $\mathrm{V}$ points, accompanied by Fe diffusion from the substrate. According to the percentage of element atoms, $\gamma$-Ni solid solution was mainly formed in this region. The solid toughness of the $\gamma$-Ni solid solution was better than WC particles, and it could provide certain deformation for the joint of the brazing seam. Compared with the $\mathrm{V}$ region, the $\mathrm{W}$ element increased obviously, while the Fe element decreased. The $\mathrm{W}$ region should be close to the WC particles. Under the action of shearing stress, cleavage fractures began to appear near WC particles because the bonding strength of the WC and filler metal was smaller than that of the filler metal and the ductility of the solder was better.

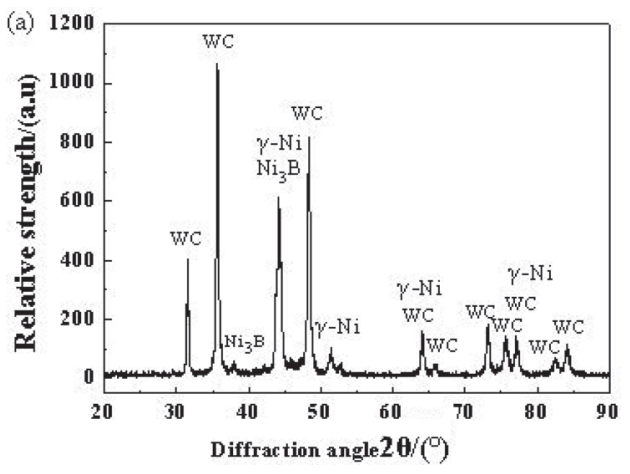

(a) Surface

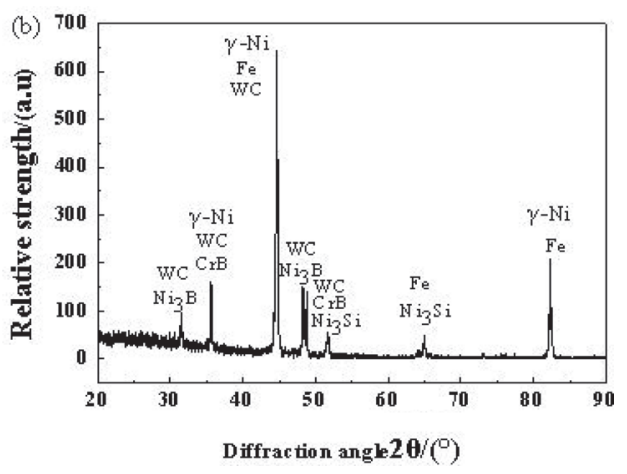

(b) Cross section

Figure 6: Surface and cross section XRD of $50 \%$ WC composite coating:(a) Surface, (b) Cross section. 


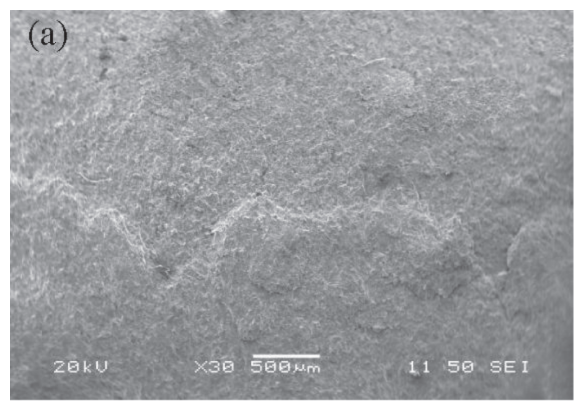

(a) Fractograph of $30 \%$ WC coating $\times 30$

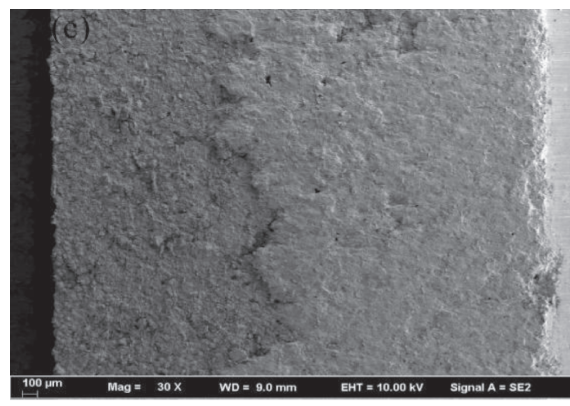

(c) Fractograph of $50 \%$ WC coating $\times 30$

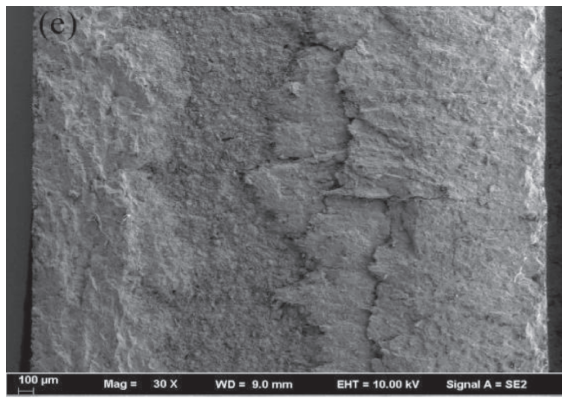

(e) Fractograph of $80 \%$ WC coating $\times 30$

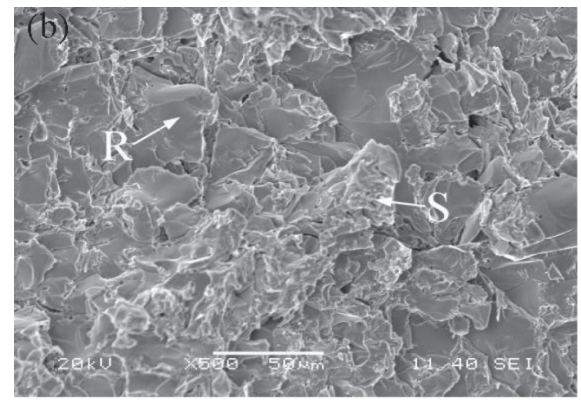

(b) Fractograph of $30 \%$ WC coating $\times 500$

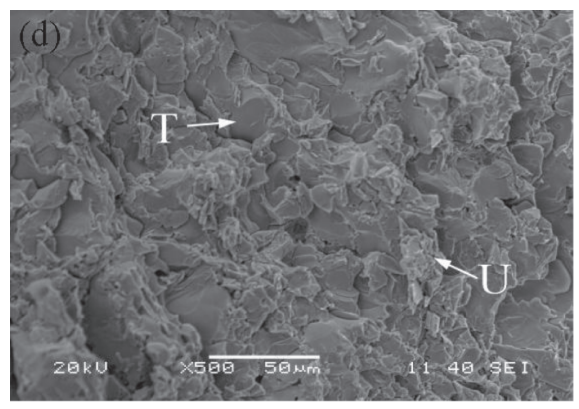

(d) Fractograph of $50 \% \mathrm{WC}$ coating $\times 500$

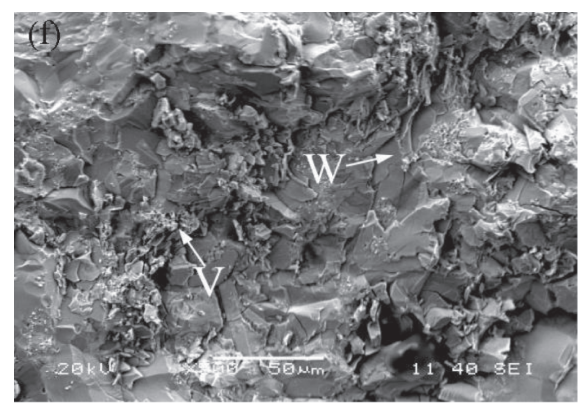

(f) Fractograph of $80 \%$ WC coating $\times 500$

Figure 7: Fractographs of three coatings at different magnification:(a) Fractograph of $30 \%$ WC coating $\times 30$, (b) Fractograph of $30 \%$ WC coating $\times 500$, (c) Fractograph of $50 \%$ WC coating $\times 30$, (d) Fractograph of $50 \%$ WC coating $\times 500$, (e) Fractograph of $80 \%$ WC coating $\times 30$, (f) Fractograph of $80 \%$ WC coating $\times 500$.

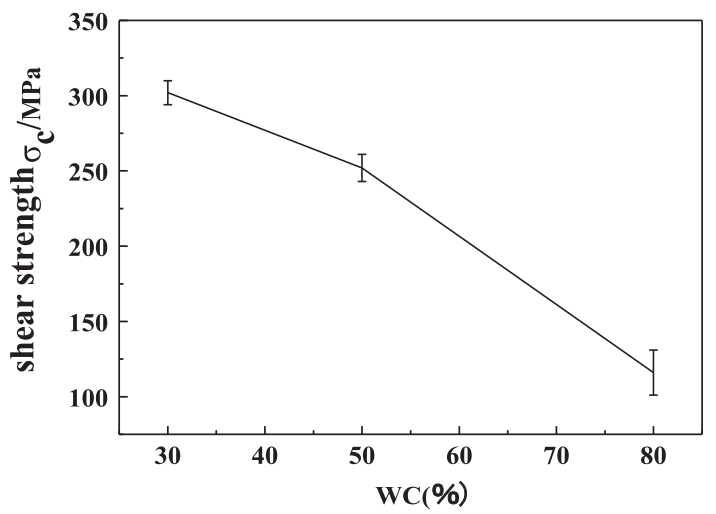

Figure 8: Shear strength of three coatings.
Table 3: Characteristic element composition of coating fracture (wt.\%).

\begin{tabular}{lrrrrr}
\hline Region & Ni & Fe & Si & Cr & W \\
\hline R & 74.30 & 9.60 & 10.53 & 5.58 & 0 \\
S & 88.70 & 6.93 & 0.49 & 3.67 & 0.2 \\
T & 45.26 & 8.72 & 12.23 & 33.79 & 0 \\
U & 61.84 & 6.33 & 4.39 & 27.44 & 0 \\
V & 34.01 & 0.52 & 14.79 & 32.41 & 18.27 \\
W & 24.20 & 0.62 & 5.69 & 21.38 & 48.11 \\
\hline
\end{tabular}




\section{Conclusion}

(1) Composite coatings with WC mass fractions of $30 \%$, 50\% and $80 \%$ were brazed onto Q345 by high temperature nickel base tape filler metal under the process parameters of a brazing temperature of $1030^{\circ} \mathrm{C}$ and a holding time of $30 \mathrm{~min}$ in a vacuum furnace with a vacuum level $>2 \times 10^{-3} \mathrm{~Pa}$. Segregation of WC particles appeared in the three coatings. With the increase of WC mass fraction, the segregation of WC particles in the coating was gradually weakened, and the WC particles were more closely arranged. Moreover, the thickness of the coating and substrate reaction layer III was narrower, and the number of holes in the coating was higher.

(2) The scanning lines of the interface between the three coatings and the substrate showed that the element $\mathrm{W}$ almost did not diffuse to the brazing seam and the substrate, while the elements $\mathrm{Ni}, \mathrm{Cr}$ and $\mathrm{Si}$ diffused to the substrate. The interface between the brazing seam and the substrate was metallurgically bonded. Compared with the $50 \%$ and $80 \%$ WC coatings, two local micro reaction zones in the $30 \% \mathrm{WC}$ coating reaction layer were formed. Near the hard side, $\mathrm{Cr}$ and Si were higher. Near the substrate side, the Ni element also occurred with more diffusion to the substrate.

(3) For 30\%, 50\% and $80 \%$ WC composite, coating shear strengths were $302 \mathrm{MPa}, 252 \mathrm{MPa}$ and 116 $\mathrm{MPa}$, respectively. With the increase of WC content, the macro fracture delamination phenomenon in the coating was more obvious. Fracture of the $30 \%$ and $50 \%$ WC coating was mainly plastic fracture, and fracture of the $80 \%$ WC coating was mainly brittle fracture and partial plastic fracture.
Acknowledgements: This project was supported by the National Natural Science Foundation of China (Grant No.51405205) and the Project Funded by China Postdoctoral Science Foundation (2015M581751).

\section{References}

[1] X. Hu and L. Wang, Surface Eng., 16 (2000) 201-204.

[2] Z. Kamdi, P.H. Shipway, K.T. Voisey and A.J. Sturgeon, Wear, 271 (2011) 1264-1272.

[3] V. Rajinikanth and K. Venkateswarlu, Tribology Int., 44 (2011) 1711.

[4] K. Liu, B. Liu, R. Villavicencio, Z.L. Wang and C. Soares, Ships Offshore Struct., 13 (2018) 217-225.

[5] D.F. Chen, Y. Xu, M.O. Tade and Z.P. Shao, ACS Energy Letters, 2 (2017) 319-326.

[6] L. Jun, Y. Shuai and X. Weisheng, J. Alloys Compd., 654 (2016) 63-70.

[7] J.S. Xu, X.C. Zhang and F.Z. Xuan, J. Mater. Eng. Perform. 21 (2012) 1904-1911.

[8] K.V. Acker, D. Vanhoyweghen, R. Persoons and J. Vangrunderbeek, Wear, 258 (2005) 194-202.

[9] S.P. Lu, Y. Guo and L.S. Chen, Acta Metallurgica. Sinica., 15 (2000) 857-861.

[10] Y. Zhou, C.Z. Xia, J. Yang, X.P. Xu and J.S. Zou, Sci. Eng. Composite Mater., 25 (2018) 17-23.

[11] C.Z. Xia, W.W. Sun, Y. Zhou and X.P. Xu, J. Alloys Compd., 741 (2018) 155-160.

[12] X. Lu, X. Feng, Y. Zuo, C. Zheng and S. Lu, Surf. Coat. Technol., 270 (2015) 227-235.

[13] L.X. Gao, T. Liu and D.Q. Zhang, Surface Interface Anal., 45 (2013) 767-772.

[14] Q.Z. Da, L. Tao, H.G. Joo, X.G. Li and Y.L. Kang, Int. J. Refract. Metals Hard Mater., 35 (2012) 246-250.

[15] S. Huang, D. Sun, D. Xu, W. Wang and H. Xu, J. Bionic Eng., 12 (2015) 592-603.

[16] G.R. Yang, C.P. Huang, W.M. Song, J. Li, J.J. Liu, Y. Ma and Y. Hao, Int. J. Minerals Metallurgy Mater., 23 (2016) 184-192.

[17] Y. Gao, B.H. Luo, K.J. He, H.B. Jing and Z.H. Bai, Vacuum, 143 (2017) 271-282.

[18] E.O. Correa, J.N. Santos and A.N. Klein, Int. J. Mater. Res., 102 (2011) 1369-1373. 